\title{
Image analysis of ocular fundus for retinopathy characterization*
}

\author{
Daniela Ushizima ${ }^{1}$, Jorge Cuadros ${ }^{2}$ \\ ${ }^{1}$ Lawrence Berkeley Laboratory, ${ }^{2}$ University of California, Berkeley
}

Automated analysis of ocular fundus images is a common procedure in countries as England, including both nonemergency examination and retinal screening of patients with diabetes mellitus. This involves digital image capture and transmission of the images to a digital reading center for evaluation and treatment referral. In collaboration with the Optometry Department, University of California, Berkeley, we have tested computer vision algorithms to segment vessels and lesions in ground-truth data (DRIVE database) and hundreds of images of non-macular centric and nonuniform illumination views of the eye fundus from EyePACS program. Methods under investigation involve mathematical morphology (Figure 1) for image enhancement and pattern matching. Recently, we have focused in more efficient techniques to model the ocular fundus vasculature (Figure 2), using deformable contours. Preliminary results show accurate segmentation of vessels and high level of true-positive microaneurysms.
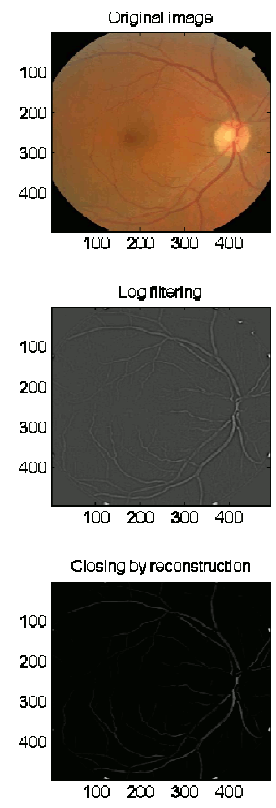
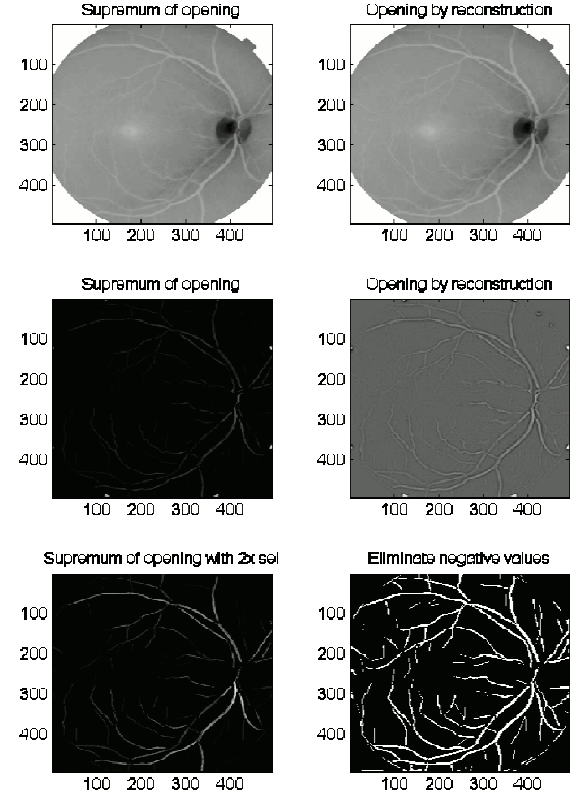

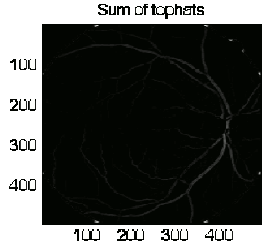

Inflmum or closing
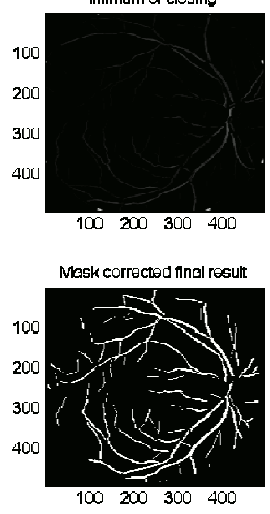

Figure 1. Vasculature segmentation using morphological methods only. 

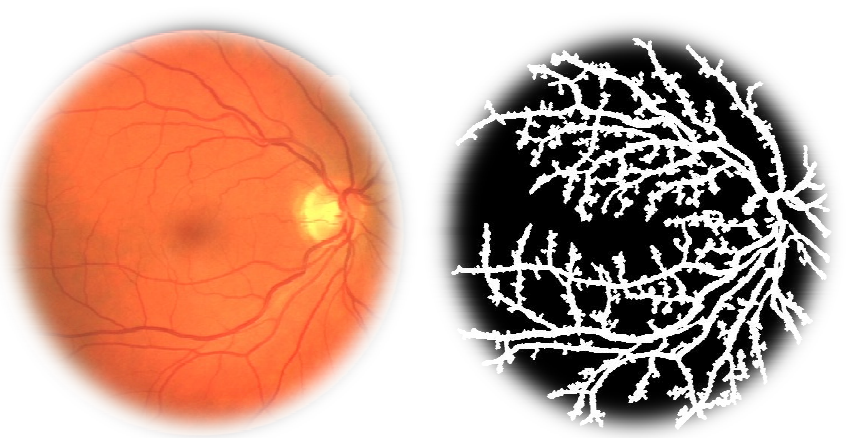

Figure 2. Vasculature segmention using fast marching methods.
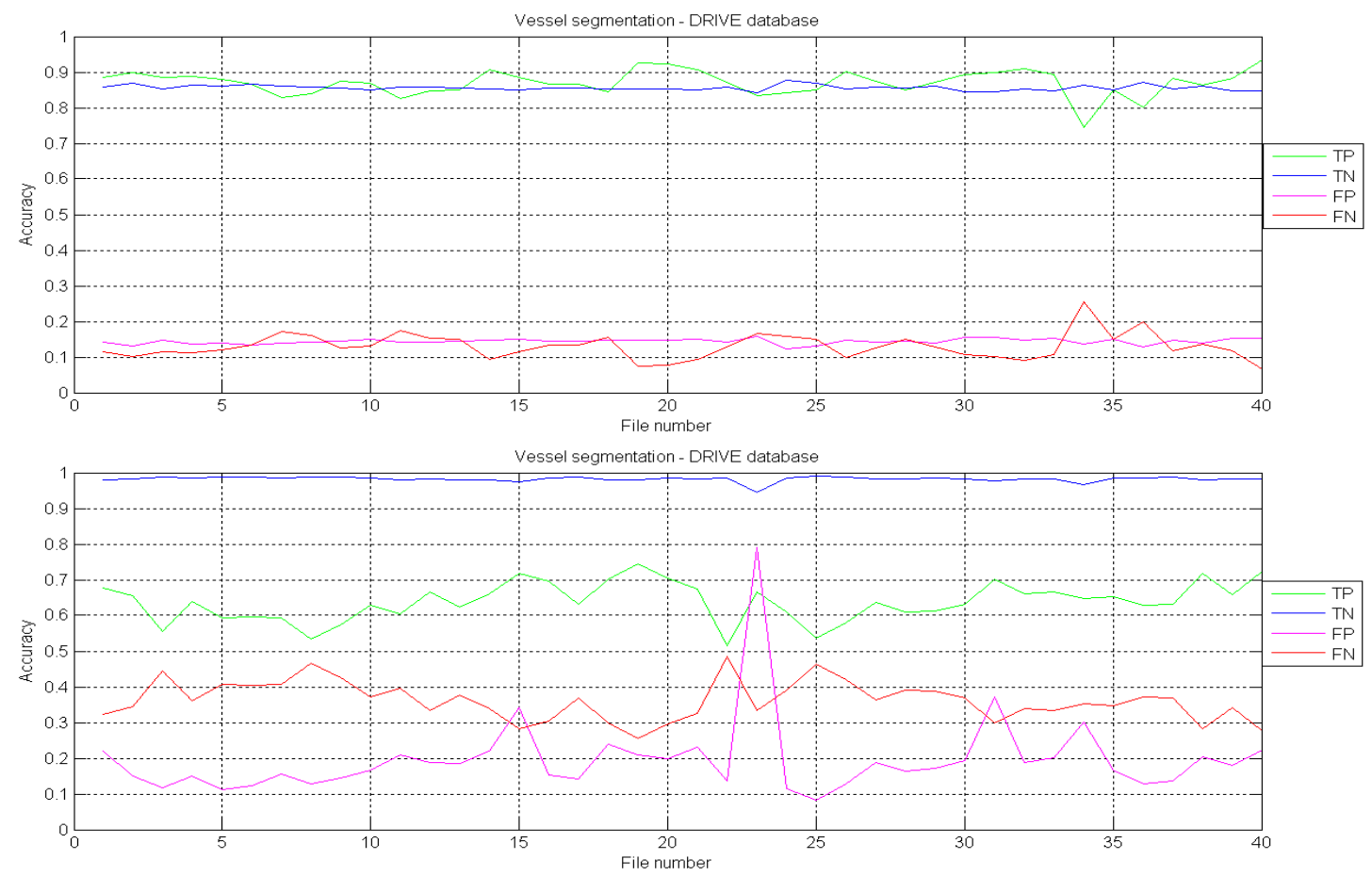

Figure 3. Vasculature segmentation accuracy using DRIVE database: (top) mathematical morphology and (bottom) fast marching. 


\section{LEGAL DISCLAIMER}

This document was prepared as an account of work sponsored by the United States Government. While this document is believed to contain correct information, neither the United States Government nor any agency thereof, nor The Regents of the University of California, nor any of their employees, makes any warranty, express or implied, or assumes any legal responsibility for the accuracy, completeness, or usefulness of any information, apparatus, product, or process disclosed, or represents that its use would not infringe privately owned rights. Reference herein to any specific commercial product, process, or service by its trade name, trademark, manufacturer, or otherwise, does not necessarily constitute or imply its endorsement, recommendation, or favoring by the United States Government or any agency thereof, or The Regents of the University of California. The views and opinions of authors expressed herein do not necessarily state or reflect those of the United States Government or any agency thereof or The Regents of the University of California. 